\title{
Prioritizing Tasks in the Cockpit: A Review of Cognitive Processing Models, Methods of Dealing with Cognitive Limitations, and Training Strategies
}

\author{
Amy L. Hoover \\ Central Washington University
}

\begin{abstract}
Pilots must continuously assess, prioritize, execute, monitor, and terminate tasks to the best of their ability to safely and effectively complete the flight mission, often in time critical situations and in a dynamic environment. Limitations on pilot abilities to multitask are related to many factors described in the literature. To better understand and manage those limitations cognitive processes, such as single channel theory, multiple channel theory, and multiple resource theory are identified and related to cognitive limitations. Methods pilots use to deal with those cognitive limitations, including attention management, workload management, and task management are explored. Results from task prioritization specific training studies indicate multitasking may be trainable. Outcomes from studies reviewed can be used to inform design and implementation of training curricula. Some strategies for design and implementation of task prioritization training are presented.
\end{abstract}

\section{INTRODUCTION}

December 28, 1978 was a clear, calm night in Portland, Oregon, and certainly not the kind of tapestry against which one would think to paint the scene of a major airline accident. But for the crew of a United Airlines DC-8 overhead the inability to properly prioritize tasks was soon to become disastrous. As the aircraft circled near the airport the captain became obsessed about a malfunction in the landing gear and allowed the aircraft to run out of fuel, even after other crew members warned him several times about the critically low fuel situation. The DC-8 crashed into a suburban neighborhood, destroying the aircraft and killing eight passengers and two crewmembers. The accident investigation report states that a major cause of the accident was the captain's "diverted attention from operation of aircraft" (National Transportation Safety Board, 1979, p. 1). When the gear malfunction initially occurred it took priority. But as the airplane burned more and more fuel the situation changed and priorities shifted. When the fuel became critically low the captain neglected the most important task (ensuring the aircraft had sufficient fuel) to attend to the landing gear, a task he should have shed as it became less urgent with respect to immediate flight safety. That type of error can be classified as a task prioritization error (Funk, Colvin, Bishara, Nicolalde, Shakeri, Chen, \&
Braune, 2003; Hoover \& Russ-Eft, 2005; Wickens, 2002), which occurs when a pilot gives preferential attention to a lower priority task rather than to a task that should take higher priority with regards to flight safety (e.g., it is more critical, more urgent, or not being performed satisfactorily).

Such prioritization errors have contributed to a significant number of aircraft incidents and accidents (Chou, Madhaven, \& Funk, 1996; Damos, 1997; Dismukes, Loukopoulos, \& Jobe, 2001; Latorella, 1996; Raby \& Wickens, 1994; Rogers, 1996; Schutte \& Trujillo, 1996). For example, Chou et al. (1996) conducted an indepth review of 324 National Transportation Safety Board (NTSB) aircraft accident reports and 470 National Aeronautics and Space Administration (NASA) Aviation Safety Reporting System (ASRS) aircraft incident reports. They found that task prioritization errors were significant in $23 \%$ of the NTSB accidents and $49 \%$ of the ASRS reported incidents.

Like the United Airlines captain, all pilots are required to perform multiple tasks simultaneously during both normal and emergency operations. Pilots must continuously assess, prioritize, execute, monitor, and shed tasks to the best of their ability, often in time critical situations and in a dynamic environment. At any given time a pilot's ability to multitask may be limited by many factors, including how 
effectively the pilot manages inputs and executes tasks to accomplish the flight mission safely and efficiently. Better understanding and managing of those limitations include identifying cognitive theories of multitasking behavior presented in the literature as well as identifying methods of dealing with cognitive limitations to pilot multitasking. Additionally, synthesis of studies that address whether cockpit task prioritization ability may be specifically trained can inform future training studies and task prioritization training programs.

\section{COGNITIVE THEORIES OF MULTITASKING BEHAVIOR}

Several theories of multitasking behavior are posited in the literature. Wickens (1992, 2002) defined multitask performance as the allocation of differentiated cognitive resources among competing tasks. Raby and Wickens (1994) explained it as an attempt to manage workload and to balance acceptable levels of performance with acceptable levels of cognitive stress. A similar presentation of multitask performance as a function of workload was given by O'Hare and Roscoe (1990), but they related performance to the ability of the pilot to time share between concurrent tasks. Kern (1998) discussed effective execution of cockpit tasks as a function of proper procedural discipline in prioritizing both inputs and tasks.

Multitasking has been recognized as a key element to successful performance in complex systems (O'Hare \& Roscoe, 1990; Raby \& Wickens, 1994; Wickens 1990, 1992, 2002; Wickens, Dixon, \& Chang, 2003). In the mid $20^{\text {th }}$ century, cognitive psychologists used computer metaphors to describe the brain and cognitive processes related to performing multiple tasks. Three basic theories of multitasking and task management that have evolved from research in cognitive psychology are 1) single channel theory, 2) single resource theory, and 3) multiple resource theory. Each of these is discussed below in the context of processes involved and limitations they present to effective multitasking abilities.

\section{Single Channel Theory}

Early researchers concluded that information must be processed sequentially based on the time available to perform tasks and that there is an overall limit on human ability to handle information and perform associated tasks (Broadbent, 1958; Lindsay \& Norman, 1972; Welford, 1952, 1967). That type of mental processing is called the "single channel bottleneck" or single channel theory (SCT), and it assumes that no parallel processing or timesharing can take place: two tasks cannot be performed concurrently, and one will be dropped until the other is completed (Moray \& Rotenberg, 1986; Wickens et al., 2003). Since SCT predicts that tasks must be performed sequentially, the following summarizes the relationship of concurrent tasks to time available:

SCT has different manifestations. All versions of strict SCT predict that progress on information processing can only take place on one task at a time, and therefore the completion time for two tasks imposed concurrently will equal the sum of the completion times for each done alone. This concurrent completion time will increase to the extent that information for a second arriving task is closer in time to the initiation of the first arriving task. (Wickens et al., 2003, p. 12)

Based on time-limited models of mental capacity described by SCT, studies done for the U.S. Navy in the 1960's to develop more efficient ways of attending to sequential tasks focused on the amount of time it took for a pilot to process a task. For example, studies done by the Boeing Company (Premesalar, 1969) determined that it took an average of 3.9 seconds for the pilot to acknowledge course data, 1.8 seconds to check attitude and heading, 3.8 seconds to change course to the new heading, and 5.0 seconds to monitor systems status. Next, procedures were developed to maximize the relationship between information processing and task performance times so pilots performed tasks in a specific sequence based on their priority and on the time allocated for each task, which optimized overall task performance (Premesalar, 1969). 
Another aspect of SCT processing identified by Moray and Rotenberg (1986) was the phenomenon of "cognitive lockup" that occurred when pilots become attentionally locked onto one task to the exclusion of other tasks. Moray and Rotenberg (1986) concluded that cognitive lockup behavior represented evidence that people deal with problems serially rather than switching between tasks. In experiments conducted by Hoover and Russ-Eft (2005) pilots exhibited cognitive lockup when they became fixated on operation of the GPS system and ignored large deviations in primary aircraft control, indicating they were processing inputs and tasks according to SCT.

\section{Single Resource Theory}

Single Resource Theory (SRT) differs from SCT in that cognitive resources, rather than amount of time available, predict task interference and performance (Wickens et al., 2003). SCT posits that there is a single pool of cognitive resources available, but those resources are undifferentiated with regards to attention, and when more than one task is performed, or when tasks become more difficult, this pool of resources become limited (Kahneman, 1973). For example, experimental subjects who were asked to process simultaneous messages could recall some characteristics of the second message, such as whether a speaker was male or female, but not the context of the message (Lindsay \& Norman, 1972). Lindsay and Norman postulated that some kind of filtering mechanism limited the overall capacity to transfer incoming sensory information into working memory. However, Moray (1967) determined that there were certain circumstances where humans had the ability to share cognitive resources between tasks, and Hoover and Russ-Eft (2005) showed that in a given scenario some pilots had the ability to share resources between two tasks simultaneously and others did not. Other studies showed that motivation and subsequent mobilization of increased effort could overcome the penalties of increased task difficulty so that two tasks could be performed simultaneously, although task performance might be degraded in one or both tasks (O'Hare \& Roscoe, 1990; Wickens et. al., 2003).

\section{Multiple Resource Theory}

Tasks that do not compete for the same resources, such as a visual task and an auditory task are easier to perform simultaneously than two tasks that use the same resources (Wickens, 1980, 1992; Wickens et al., 2003) which represent application of the multiple resource theory (MRT) model of cognitive processing first described by Wickens (1980). For example, monitoring flight instruments is a visual and spatial task, whereas listening and responding to an air traffic control clearance is an aural and verbal task. Because spatial and verbal tasks operate in distinctly different ways and take place in separate parts of the brain, there will be less conflict between those types of tasks, because they are not competing for the same mental resources. If tasks are competing for the same type of resources, then task performance for both tasks may deteriorate as resources are reduced (Wickens et al., 2003). A practical application of MRT includes cockpit design items such as voice activated control systems and auditory displays, which are less likely to interfere with the primarily visual spatial task of flying (Liu \& Wickens, 1992; O'Hare \& Roscoe, 1990; Wickens et al., 2003).

One aspect of MRT involves the concept of time-sharing, or the ability to alternate between different sources of information (Wickens et al., 2003). During initial training the majority of a pilot's time is spent focusing on the primary task of learning to control the aircraft, but as skill and confidence are gained more time becomes available to share attention with other tasks such as scanning for traffic, monitoring instruments, and assessing the status of current and future situations. The ability to perform tasks concurrently and efficiently depends not only on time-sharing ability but also on the cognitive resources or processing demands imposed by each individual task (North, 1977; Wickens, 1980; Wickens, Vidulich, \& Sandry-Garza, 1984).

The way in which a pilot allocates cognitive resources to perform multiple concurrent tasks is an important aspect of multitasking theory. Regardless of what theory is used to describe how a pilot processes information and performs tasks, limitations to cognitive resources hinder a pilot's ability to 
allocate those resources and present a challenge to flight operations and flight safety.

\section{METHODS OF DEALING WITH COGNITIVE LIMITATIONS}

A certain level of multitasking ability that can be described by one or more cognitive processing models (SCT, SRT, and/or MRT) is required to perform even at a basic skill level adequate to achieve pilot certification, and individualized skills may vary from one pilot to another. However, pilots will be limited in varying degrees by their ability to prioritize and execute tasks in the context of flight operations. This section draws from literature that focuses on ways in which a pilot can deal with limitations related to cognitive processing and to use cognitive resources in managing attention, workload, and prioritizing flight tasks.

\section{Attention Management}

One approach to multitasking in the cockpit focuses on managing pilot attention with respect to inputs and to prioritization and execution of tasks. Kern (1998) put it this way:

"Attention management is a very complex phenomenon involving both the conscious and subconscious. It keys off of pattern recognition, or the ability of the brain to make sense out of multiple inputs by arranging them to fit patterns it has seen before. Often in aviation, there is no pattern established in your memory banks for a new situation, and this can lead to severe task saturation and channelized attention, two of the grim reaper's favorite tools for use on aviators. In order to make sure that we have the necessary attention available to complete mandatory procedures, we must learn to manage our attention.” (p. 90)

Kern (1998) also described occurrence of task saturation as a result of two different situations. The first is information overload, where the brain's ability to comprehend is simply overwhelmed by the mass of sensory input. As described by SRT this would result in degradation in performance of one or more tasks as cognitive resources become limited (O'Hare \& Roscoe, 1990; Wickens et. al., 2003). The second situation described by Kern (1998) occurs when a pilot fails to adequately prioritize inputs so that unwise time-sharing between important and unimportant tasks occurs. According to MRT, that inability to effectively time-share is linked to the level of cognitive resources required to process each input, regardless of its level of importance. Attention failures are also linked to errors such as breakdown in visual scan patterns, task fixation, and even inadvertent activation of controls such as that which lead to the crash of Eastern Airlines Flight 401 into the Florida Everglades in December, 1972 (Shappell and Wiegmann, 2001). In the Flight 401 crash the crew became fixated on a landing gear indicator light and one of them bumped the control yoke causing the autopilot to initiate a descent that caused the airplane to crash into the ground (National Transportation Safety Board, 1972). Shappell and Wiegmann (2001) compared that accident to a driver who is in hurry, or daydreaming, and misses an exit. They added, "These are both examples of attention failures that are commonly occurring highly automated behavior. While at home or driving around town, these attention failures may merely be frustrating. However, in the air they can become catastrophic" (Shappell \& Wiegmann, 2001. p. 63).

In order to effectively prioritize inputs and actions "one key is to stay ahead of the aircraft and to use times of relatively low workload to accomplish future tasks" (Kern, 1998, p. 90). Kern described a second "indispensable survival tool for pilots when dealing with task saturation is a system for prioritization when the stuff hits the fan" (p. 91) and pointed out that pilots must not only be able to prioritize tasks, but also be able to prioritize information and input to avoid time-sharing between important and unimportant tasks; failure to do so can result in channelized attention or task overload, which is a major cause of breakdown in procedural discipline. It follows that in order to effectively execute tasks with proper priority and avoid task saturation pilots must learn to manage their attention. Kern (1998) emphasized that procedural discipline is the best solution for prioritization during busy times and that pilots should use an "aviate, navigate, communicate” (ANC) hierarchy to 
assist with prioritization. Chappell (1998) amplified this concept with the following words:

From the very first flight lesson, we were taught to "aviate, navigate, communicate," in that order. To aviate, navigate, and communicate, you must be aware of the plane, the path, and the people (crew, passengers, dispatchers, and air traffic controllers). Not only do you need to monitor and evaluate these three things now, but also you need to anticipate what's going to happen in the future and consider contingencies. The current and future state of the plane, the path, and the people are the components of the plan. (pp. 249-250)

As discussed by Kern (1998) and Chappell (1998), flight training places strong emphasis on procedural discipline as paramount to managing attention; when sensory overload, interruptions, and distractions threaten flight safety, procedures may be all pilots have to fall back on to prioritize their inputs, tasks, and actions.

\section{Workload Management}

The ability to prioritize tasks is closely related both to a pilot's ability to focus attention and their ability to manage workload (Kern, 1998; Wickens, 2002, Wickens et al., 2003). A majority of accidents occur during periods of high workload, which include takeoff, approach, and landing, and effective workload management is paramount to avoiding distractions during critical flight times (Chappell, 1998; Federal Aviation Administration, 1999; Jeppesen, 2006; Kern, 2001). From an aviation psychology perspective workload seems to be a variable concept depending on the ability of the pilot or crew and on their preparation and planning strategies and practices. With certain combinations of tasks, individuals differ in their ability to process simultaneous inputs (Braune \& Wickens, 1986). Wickens (1992) determined that individuals have an optimal level of workload and that above or below that level both individual and composite task performance is diminished:

Mental workload can be described as the relationship between resource supply and task demand. If supply exceeds demand, then performance is constant. But if demand exceeds supply, then performance will decrease as the resource demand (workload) further increases. Each of the pilot's responsibilities impose a certain amount of demand. The question is how much supply the pilot has available to cope with that demand, and when the demand reaches a point where performance drops due to a lack of resources. (Wickens et al., 2003, p. 3)

During initial training pilots are introduced to the concept of workload: "Effective workload management ensures that essential operations are accomplished by planning, prioritizing, and sequencing tasks to avoid work overload" (Jeppesen, 2003, p. 3-34).

While the ability to manage workload may be highly individual, both practice and adherence to procedures can contribute to increased ability to manage workload effectively in the cockpit (Chappell, 1998; Kern, 1998).

\section{Task Management}

Rather than focusing on workload management, some studies have approached multitasking from the concept of task management, which entails managing discrete tasks, rather than total workload, by continuously prioritizing concurrent tasks and allocating resources to them based on perceived priority (Funk et al., 2003; Raby \& Wickens, 1994; Rogers, 1996; Schutte \& Trujillo, 1996). As defined by Funk (1991) and Funk et al. (2003), concurrent task management (CTM) is an ongoing process by which pilots initiate new tasks, monitor on-going tasks, selectively prioritize tasks, and terminate, or shed tasks deemed less important or that have been completed:

CTM is not new; in fact, pilots have always done it. CTM is a cognitive function that is intuitively well understood by pilots and almost always performed satisfactorily. However, there are many documented instances in which tasks were not managed properly, resulting in an aircraft incident or accident (Chou et al, 1996). Often, during critical phases of flight, this form of human error results in minor regulations violations or unsafe conditions that are rectified before a more serious situation develops. However, 
the consequences of improper CTM can be a catastrophic event resulting in many fatalities and loss of the aircraft. (Funk et al., 2003, p. 9)

Another factor that seems to affect task management performance is the type of task being performed, as described by MRT. Liu and Wickens (1992) conducted experimental studies in which pilots were assigned a primarily visual task of tracking a course and then asked to perform either a spatial decision task (e.g., predicting the future position of a vector) or a verbal task, such as mental arithmetic. Those studies found that an inherently spatial visual scanning task produced more interference with a concurrent spatial task than with a concurrent verbal task and that pilots were better at performing concurrent tasks that used different cognitive resources such as a visual task coupled with an auditory task: "tracking error, decision accuracy, and workload all suffered more when both tasks involved spatial activities" (Liu \& Wickens, 1992, p. 141). Wickens et al. (2003) stated that increased perceptual competition disrupts a cognitive task more than a motor task:

Primary task performance can suffer immensely while a pilot focuses most, or all, of her attention on dealing with the secondary task. When designing a system that requires a cognitively challenging secondary task, it is important to determine exactly how that secondary task will affect performance in other concurrent tasks. (p. 8)

In order to improve task prioritization Wickens (2002) suggested using an aviate, navigate, communicate, operate systems (ANCS) hierarchy to prioritize tasks. However, even when using such a method, the extent to which the hierarchy is maintained when an ongoing task is interrupted by an incoming task can depend on the type of interrupting task:

Some evidence suggests that auditory tasks low on the ANCS hierarchy, and particularly auditory communication tasks, tend to be both more interrupting and less interruptible than tasks with a higher priority (e.g. navigation). Studies comparing better and more poorly performing pilots have indicated that better multitask performance results from rapid switching between tasks (Wickens, 2002, p. 132).

Experiments conducted by Hoover and Russ-Eft (2005) corroborated the tendency of auditory communication tasks to be more interrupting. Using the ANC hierarchy to define task priorities, their experiments interrupted the pilot's primary task, such as basic aircraft attitude control, with a lower priority task, such as tracking or intercepting a course or responding to air traffic control instructions. Hoover and Russ-Eft (2005) found that pilots tended to misprioritize tasks as much as $47 \%$ more frequently when the interruption involved a communications task rather than a visual navigation task.

The tendency for a lower priority communications task to interrupt a higher priority aviation or navigation task cited by Wickens (2002) and Hoover and Russ-Eft (2005) supports anecdotal wisdom in the flight training industry that pilots will typically place communications first on the list of tasks, even when they know it should be lowest priority. Popular aviation magazines that target student pilots and flight instructors repeatedly publish articles addressing this issue of task misprioritization. For example, Miller (2003) wrote: "You may not have heard of Marconi's law. Named somewhat facetiously for Guglielmo Marconi, who transmitted the first wireless message in 1895, it says, 'fly the airplane, not the radio!'" (p. 38)

\section{RELATIONSHIP OF ATTENTION, WORKLOAD, AND TASK MANAGEMENT}

Although some researchers address workload and task management separately, many studies show a strong relationship between pilot workload and the ability to effectively prioritize and execute tasks. Raby and Wickens (1994) investigated how the pilots decided to prioritize tasks and shed tasks once they were completed and determined that people adapt to high workload periods by prioritizing tasks; the higher the priority, the closer the task was performed at the optimal time. In their study, 30 student pilots flew three simulated landing approaches under low, medium, and high 
workload scenarios. As workload increased, some pilots' performance on primary tasks (flying the airplane) diminished to the point of creating dangerous situations. The inverse relationship of task prioritization performance to pilot workload was corroborated through empirical studies conducted by Chou et al. (1996) and Wickens et al. (2003). Those studies found that pilots mis-prioritized tasks more frequently during periods of high workload.

A significant outcome of Raby and Wickens (1994) study was that individuals assume or shed tasks in order to maintain workload at a relatively constant level which varies with the individual. Pilots who were most successful were those who scheduled discrete tasks during periods of low workload (Raby \& Wickens, 1994). Wickens (2002) wrote, "Task management is directly related to mental workload as the competing demands of tasks for attention exceed the operator's limited resources" (p. 128). Indeed, a critical factor is for pilots to stay ahead of the aircraft and use times of relatively low workload to accomplish future tasks, which requires a high level of discipline (Chappell, 1998; Kern, 1998).

Strategies used to deal with cognitive limitations and to facilitate cockpit multitasking performance center on pilot ability to manage attention and workload, and effectively prioritize and allocate tasks. Ultimately, those allocations should be based on which tasks are most critical at the time with regards to flight safety and performance. Because often the number of concurrent tasks is great and because in many cases each task is critically important to flight safety, pilots are accustomed to relying on standard operating procedures (SOPs) checklists, cockpit flow checks, and mnemonic memory aiding devices (such as the ANC hierarchy), with the assumption that by following those procedures they are conducting tasks in the proper sequence. Additionally, engine and systems controls, fuel selectors, switches, and other important items may be positioned so the pilot can perform tasks in a certain sequence (for example left to right or up to down) as part of a flow check. Procedures and checklists may be constructed so that pilots perform tasks in an exact sequence, often in the order of importance or highest to lowest priority. However, task priorities will change, and when a pilot must rapidly switch between tasks, or when unexpected events require actions that are not a part of standard or emergency checklists and procedures, some highly cognitive tasks, such as maintaining situational awareness, cannot be easily codified in checklists and procedures and it is difficult for any hierarchical scheme to stand up completely under close scrutiny (Wickens, 2002).

\section{TRAINING IN ATTENTION, WORKLOAD, AND TASK MANAGEMENT}

A pilot's ability to always be aware of the tasks that need to be performed and in what order they must be performed is critical, and begs the question as to whether attention management, workload management, and task prioritization are improved solely through experience gained, or whether they can be improved through specific training. Based on empirical findings, O'Hare and Roscoe (1990) stated that "It is possible to perform certain nonconflicting tasks concurrently without decrement to either, and workload studies have shown that this can indeed be the case" (p. 193). However, they noted that experts' and novices' performance varied significantly and concluded that extensive practice that comes with flight experience is necessary to improve the ability to time share between tasks and perform multiple tasks concurrently. Conversely, other experimental studies show evidence that training specific to task management improved cockpit multitasking performance (Gabriel \& Burrows, 1968; Hoover \& Russ-Eft, 2005; Premesalar, 1969).

Hoover and Russ-Eft (2005) conducted experiments with university flight students who exhibited equivalent task prioritization performance in the context of the ANC hierarchy. After two weeks, students who received task prioritization specific training showed as much as a $56 \%$ reduction in multitasking errors, while students that did not receive training showed no significant change (Hoover \& Russ-Eft, 2005). However, their study did not address longer term effects of the training. In a study conducted with U.S. Marine aviators (Gabriel \& Burrows, 1968), pilots were 
trained to prioritize cockpit tasks and to acquire all necessary information from cockpit instruments before refocusing their attention outside. Pilots who had this training were much better at detecting external targets than those who were not trained, even several months after the training had occurred (Gabriel \& Burrows, 1968), which indicates they were better able to divide their attention and resources as a result of specific training.

\section{DESIGN OF FLIGHT TRAINING CURRICULA}

Flight instructor training curricula based on FAA standards addresses training in task prioritization, attention management, workload management (FAA, 1999; Jeppesen, 2006a). Despite that apparent emphasis, misprioritization of cockpit tasks had contributed to a significant number of aircraft incidents and accidents as previously discussed. It is possible that although concepts of multitasking, workload management, and task prioritization training are introduced, they may be lost in the larger scope of components required by a typical training curriculum and environment. Alternatively, it may be that the manner in which the concepts are introduced and practiced do not lend themselves to effectively developing strategies to overcome the cognitive limitations just described.

According to the dual memory model of learning and retention as described by Schunck (2004) and adopted by the FAA in their flight instructor training literature (Federal Aviation Administration, 1999), information is processed through inputs (primarily visual and auditory) to the sensory register. In order to transfer information to long term memory the learner must relate incoming information to concepts and ideas already in memory. Therefore, in order to be effective, training curricula must include the linking of multitasking and prioritization skills to a pilot's existing core of experience and practice during flight training. Training must also facilitate higher levels of learning by developing the pilot's ability to correlate what they learn from the specific training to general flight operations.
Several training strategies are suggested here that could be used to incorporate cognitive processing models and methods of dealing with cognitive limitations in the design and implementation of training curricula. One strategy is to place pilots in situations where they experience limitations just discussed such as sensory overload or cognitive lockup and are given the opportunity afterwards to self-analyze and reflect on strategies they used (or did not use) to deal with the situation. An effective way to do that is to make a video recording of the session for playback and analysis. Scenario based training is ideal for designing these types of sessions and can be used in simulator sessions as well as more limited use in the aircraft.

Another method is to have pilots conduct analysis of accidents and incidents taken from the NTSB and NASA databases with respect to multitasking errors. After analysis, pilots should recreate the accident and incident scenarios and provide possible points in time at which a different action or decision with respect to attention or workload management or task prioritization could have changed the outcome of the flight.

Exercises in which pilots reflect on a flight with respect to multitasking concepts and strategies they used for in-flight decision making can also be designed, and both written reflection and verbal debriefings can be used. The reflection should include emphasis on procedural discipline, adherence to SOPs, checklists, briefings, flow checks, and mnemonic memory aids at appropriate times in order to link concepts to task prioritization and attention and workload management to task performance. Additionally, learning sessions can be designed to include role-playing scenarios to give pilots insight into their reactions and behavior in the cockpit when confronted with cognitive limitations and multitasking challenges. 


\section{REFERENCES}

Braune, R. J., \& Wickens, C. D. (1986). Time-sharing revisited: Test of a componential model for the assessment of individual differences. Ergonomics, 29, 1399-1414.

Broadbent, D. (1958). Perception and communications. New York, Permagon Press.

Chappell, S. L. (1998). Disciplined attention, The next best thing to a crystal ball. In T. Kern, Flight discipline. New York: McGraw-Hill.

Chou, C. D., Madhavan, D., \& Funk, K. H. (1996). Studies of cockpit task management errors. The International Journal of Aviation Psychology, 6(4), 307-320.

Damos, D. L. (1997). Using interruptions to identify task prioritization in part 121 air carrier operations. Proceedings of the Ninth International Symposium on Aviation Psychology(4), Columbus, OH, April 27 - May 1. 1997.

Dismukes, R. K., Loukopoulos, L. D., \& Jobe, K. K. (2001). The challenges of managing concurrent and deferred tasks. In R. Jensen (Ed.), Proceedings of the 11th International Symposium on Aviation Psychology. Columbus, OH: Ohio State University.

Federal Aviation Administration. (1999). Aviation instructor's handbook (FAA-H-8083-9). Washington D.C.: U.S. Government Printing Office.

Funk, K. H. (1991). Cockpit task management: Preliminary definitions, normative theory, error taxonomy, and design recommendations. The International Journal of Aviation Psychology, 1(4), 271-285.

Funk, K. H., Colvin, K., Bishara, S., Nicolalde, J., Shakeri, S., Chen, J. Y., \& Braune, R. (2003). Training pilots to prioritize tasks: Theoretical foundations and preliminary experiments. NASA Grant NAG 2-1287 Final Report. Corvallis, Oregon.

Gabriel, R. G., \& Burrows, A. A. (1968). Improving time-sharing performance of pilots through training. Human Factors, 10, 33-40.

Hoover, A.L., \& Russ-Eft, D.F. (2005). Effect of concurrent task management training on single pilot task prioritization performance. International Journal of Applied Aviation Studies, 5(2).

Jeppesen (2006a). Flight instructor manual. Englewood, CO: Author.

Jeppesen (2006b). Private pilot manual. Englewood, CO: Author.

Kahneman, D. (1973). Attention and effort, Englewood Cliffs, NJ: Prentice-Hall.

Kern, T. (1998). Flight discipline. New York: McGraw-Hill.

Kern, T. (2001). Controlling pilot error, culture, environment, \& CRM. Chicago: McGraw-Hill.

Latorella, K. A. (1996). Investigating interruptions: An example from the flightdeck. Proceedings of the Human Factors and Ergonomics Society 40 ${ }^{\text {th }}$ Annual Meeting. pp.249-253.

Lindsay, P. H., \& Norman, D. A. (1972). Human information processing. London: Academic Press.

Liu, Y., \& Wickens, C. D. (1992). Visual scanning with or without spatial uncertainty and divided and selective attention. Acta Psychologica, 79, 131-183.

Miller, W. (2003, December). Fly, listen, talk: In a moving airplane, actions may speak louder than words. AOPA Flight Training. Frederick, MD: AOPA Membership Publications.

Moray, N. (1967). Where is capacity limited? A survey and a model. Acta Psycholotica, 27, 84-92. 
Moray, N., \& Rotenberg, I. (1986), Fault diagnosis in process control. Annual proceedings of the Human Factors Association of Canada, Montreal.

National Transportation Safety Board, 1979. Accident report NTSB DCA79AA005. Seattle, WA: U.S. Department of Transportation.

National Transportation Safety Board, 1972. Accident report NTSB DCA73AZ005. Miami, FL: U.S. Department of Transportation.

North, R. A. (1977). Task functional demands as factors in dual-task performance. Proceedings of the $21^{\text {st }}$ Annual Meeting of the Human Factors Society. Santa Monica: Human Factors.

O'Hare, D., \& Roscoe, S. (1990). Flightdeck performance:, The human factor. Ames, IA: Iowa State University Press.

Premeseler, J. (1969). Declassified technical report, U.S. Navy ergonomics and human factors research division. Seattle, WA: Boeing Aircraft.

Raby, M., \& Wickens, C. D. (1994). Strategic workload management and decision biases in aviation. The International Journal of Aviation Psychology, 4(3), 211-240.

Rogers, W. H. (1996). Flight deck task management: A cognitive engineering analysis. Proceedings of the Human Factors and Ergonomics Society $40^{\text {th }}$ Annual Meeting, 239-243.

Schunk, D. H. (2004). Learning theories: An educational perspective (4 ${ }^{\text {th }}$ ed.). Englewood Cliffs, NJ: Prentice-Hall.

Schutte, P. C., \& Trujillo, A C. (1996). Flight crew task management in non-normal situations. Proceedings of the Human Factors and Ergonomics Society $40^{\text {th }}$ Annual Meeting, 244-238.

Shappell, S. A., \& Weigmann, D. A. (2001). Applying reason: The human factors analysis and classification system (HCFACS). Human Factors and Aerospace Safety, 1(1), 59-86.

Welford, A. T. (1952). The 'psychological refractory period' and the timing of high speed performance-A review and a theory. British Journal of Psychology, 43, 2-19.

Welford, A. T. (1967). Single channel operation in the brain. Acta Psychologica, 27, 5-21.

Wickens, C. D. (1980). The structure of attentional resources. In R. S. Nickerson (Ed.), Attention and performance VIII, (pp. 239-257). Hillsdale, NJ: Erlbaum.

Wickens, C. D. (1990). Resource management and time-sharing. In J. I. Elkind, S. K. Card, J. Hochberg, \& B. M. Huey (Eds.). Human performance models for computer-aided engineering. Boston: Academic Press.

Wickens, C. D. (1992). Engineering psychology and human performance (2 ${ }^{\text {nd }}$ ed.). New York: Harper Collins Publishers.

Wickens, C. D. (2002, August). Situation awareness and workload in aviation. Current Directions in Psychological Science, 11(4), 128-133.

Wickens, C. D., Dixon, S., \& Chang, D. (2003). Using Interference Models to Predict Performance in a Multiple-Task UAV Environment - 2 UAVs (Technical Report AHFD-03-9/MAAD-03-1). UrbanaChampaign, IL: University of Illinois Aviation Human Factors Division Institute of Aviation.

Wickens, C. D., Vidulich, M. A., \& Sandry-Garza, D. L. (1984). Principles of S-C-R compatibility with spatial and verbal tasks: the role of display-control location and voice interactive display-control interfacing. Human Factors, 26, 533-543. 